IV Congreso Internacional Estética y Política Poéticas del desacuerdo para una democracia plural 16 y 17 de octubre. Valencia

Doi: http://dx.doi.org/10.4995/CEP4.2019.10505

\title{
Alianzas postcapitalistas: compendio de prácticas autocríticas sobre la propiedad privada.
}

\author{
Giulia Perli y Mery Sut Favaretto
}

Universidad Politécnica de Valencia, giuliaperlatempesta@gmail.com; Investigadora independiente, meryfavaretto@ gmail.com

\begin{abstract}
One of the topics the current crisis of the democracies has addressed is revealed in the dimension of everyday life and the interest in understanding ways of living together. This contribution posits the analysis of self-narratives in which awareness processes and practices that question the notion and use of private property are evidenced. Understood as the basis of the conservative and individualistic identity construction of capitalism, modernity and colonialism, the private property (Engels, 1970) is an element experienced every day. In an intersectional view, the feminist criticism of the patriarchal structures of heritage transmission intersects with the practices and value exchange of non-Western people in diaspora, generating crosssectional anti-capitalist and anti-racist alliances (Iveković, 2015). As a result of what has been lived in keurgumak-casa grande (ideadestroyingmuros, 2015), in this contribution we will highlight experiences of community living involved in rethinking the relationships that connect private property with spaces, children, nature, economies and the transmission of inheritance. They are narratives of post-capitalist life practices that puts interdependence at the center and evade from binarism between private property and communism proposing the community experience of private property as a post-exotic alternative (Alga, 2018).
\end{abstract}

Keywords: private property, enclosures, reproductive labor, surplus value, becoming communal, communal breeding, post-exotic, keurgumak.

\footnotetext{
Resumen

Uno de los aspectos de la actual crisis de las democracias se revela en la dimensión de lo cotidiano e interesa las formas de la convivencia.

Esta contribución propone el análisis de auto-narraciones en las cuales se evidencian procesos de concienciación y prácticas que cuestionan la noción y el uso de la propiedad privada.

Entendida como fundamento de la construcción identitaria individualista y conservadora propia del capitalismo, de la modernidad y del colonialismo, la propiedad privada (Engels, 1970) es un elemento que se presenta cada día.

En una visión interseccional, la crítica feminista hacia las estructuras patriarcales de transmisión de los patrimonios se cruza con las prácticas y los valores de intercambio de personas no occidentales en diáspora, generando alianzas transversales anticapitalistas y antirracistas (Iveković, 2015).

A raíz de lo vivido en keurgumak-casa grande (ideadestroyingmuros, 2015), en esta aportación destacaremos experiencias de convivencia comunitaria implicadas en repensar las relaciones que vinculan la propiedad privada con los espacios, los/as niños/as, la naturaleza, las economías y la transmisión de la herencia.

Son narraciones de prácticas de vida postcapitalista que ponen en el centro la interdependencia y salen del binarismo entre propiedad privada y comunismo proponiendo la vivencia comunitaria de la propiedad privada en cuanto alternativa posexótica (Alga, 2018).
}

Palabras clave: propiedad privada, cercamientos, trabajo reproductivo, plusvalor, devenir comunitario, crianza comunitaria, postexótico, keurgumak 


\section{Los nuevos cercamientos}

En enero 2019 nos sorprendemos al ver que Mbacke Kadior, un pueblo en construcción y destino espiritual para la población mourid y baye fall del interior de Senegal, es como si fuera una casa grande al aire libre. Allí las habitaciones son cabañas necesarias para dormir y tener intimidad, el resto de los espacios son comunes y -en su mayoría- no tienen paredes, sino plantas y estructuras hechas con palos y techos de mimbre para tener sombra. Hay espacio para estar juntos/as, para comer, meditar, trabajar o caminar, todo sin paredes ni separaciones. Es una forma de estar que de repente nos devuelve la experiencia de la vida comunitaria en un entorno más natural.

Aquí en Occidente "según la tradición marxista, los cercamientos eran el punto de partida de la sociedad capitalista. Han sido el dispositivo básico de la "acumulación original" que ha creado una población de trabajadores libres de todos los medios de reproducción, por lo tanto forzados a trabajar por un salario. Sin embargo, los cercamientos no son un proceso que se haya agotado en los albores del capitalism sino que reaparecen regularmente en el camino de la acumulación y constituyen un componente estructural de la lucha de clases" (Federici, 2018, p. 33).

De alguna forma con los cercamientos nace una división, una lejanía entre los/as habitantes (y trabajadores/as directos/as) del territorio, con la tierra. Siguiendo la línea materialista de Engels propuesta en "El origen de la familia" (Engels, 1970) la constitución de la estructura de la familia en el contexto occidental viene siendo una forma de vallar las relaciones entre mujer e hijos/as. Para Engels uno de los fines de la familia heteromonógama occidental era asegurar que la riqueza de los varones propietarios pasará exclusivamente a los miembros de su linaje, manteniéndose así el patrimonio familiar. De esta forma las mujeres pasaban a ser meros instrumentos de procreación y renovación de los herederos. Según Silvia Federici, la separación -llevada a cabo en los últimos siglos por parte del patriarcado y del capitalismo- de la mujer del control sobre su propio cuerpo tiene una estrecha relación con las prácticas de los cercamientos y de generación de plusvalía, un aspecto fundamental para la reproducción de la fuerza de trabajo, a través del trabajo doméstico y de los cuidados.

La "crisis de la deuda" con su "ajuste estructural” impuesto por el Banco Mundial y el FMI, los procesos de gentrificación y el "colapso del socialismo" son considerados, de acuerdo con Federici, aspectos de un solo proceso: los "nuevos cercamientos" que deben operar en todo el planeta de diferentes maneras pero que en realidad son totalmente interdependientes. El capitalismo sería de esa manera una forma de cercamiento constante, pues es la separación violenta del vínculo directo el que genera la posibilidad de que la mercancía exista.

Por lo tanto si los cercamientos son el símbolo del cierre de un territorio que sellan la propiedad privada, podemos decir que, de la misma forma, la casa es el territorio de la familia nuclear delimitado por otros cercamientos que aseguran la transmisión del patrimonio patriarcal y tiene como seguro la propiedad privada. La puerta es el pasaje que permite la entrada y salida de dicha propiedad. En lo cotidiano, la puerta es frontera donde solo una llave permite el acceso y la salida que simboliza -acercándonos a la dimensión de lo cotidiano en nuestras casas- el concepto de cercamiento que Federici nos propone. La conexión entre acumulación y necesidad de seguridad encuentra en la llave un símbolo de protección.

El capitalismo necesita que la propiedad privada alcanze siempre nuevos mercados, realizando propaganda con poblaciones que vienen de culturas y valores diferentes.

\section{Las llaves y el sentimiento de propiedad}

En el año 2013 la Fundación IKEA lanzó su refugio de emergencia Better Shelter ${ }^{l}$ para ofrecer una alternativa a las tiendas de campaña que se utilizaban a menudo para albergar a familias afectadas por desastres naturales, refugiados/as y/o desplazados $/ \mathrm{as}^{2}$.

\footnotetext{
${ }^{1}$ BETTER SHELTER - A HOME AWAY OF HOME <http://bettershelter.org> [Consulta: 12 de septiembre 2019].
}

${ }^{2}$ Desde el año 2015 ACNUR ha ordenado unos 15.000 refugios que han sido desplegados por la agencia de refugiados en siete países entre ellos Grecia, Iraq, Djibouti, Chad y Serbia, en ciudades del norte de Irak, Erbil y Sulaymaniyah, en la frontera con Siria y también en la isla de Lesbos, Grecia. 
Según una conferencia celebrada en el Museo de Arte de Tel Aviv los refugios están hechos para ser "unidades de una sola habitación que en los campamentos ofrecen a los/as refugiados/as más dignidad, seguridad y privacidad que las carpas que se utilizaron desde la Segunda Guerra Mundial"3. Según Märta Terne, la gerente de comunicaciones de Better Shelter "trasladarse a un refugio significa que podría ser su hogar por un tiempo, ser capaz de cerrar una puerta a tu paso -y bloquearla- significa mucho"4.

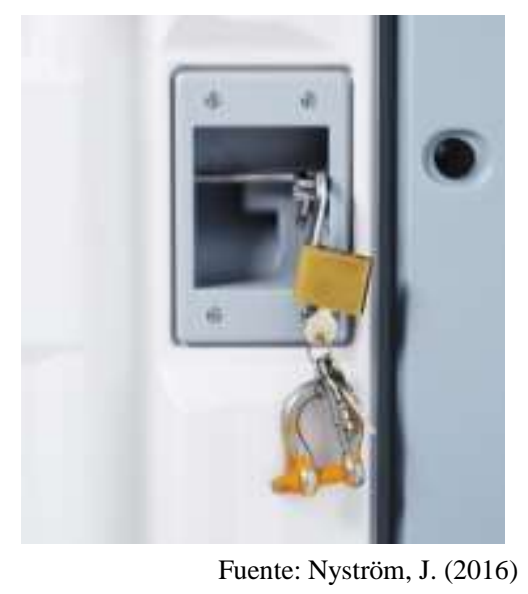

Fig. 1: Detalle de la cerradura de los refugios permanentes.

Una de las componentes de ideadestroyingmuros ${ }^{5}$ nos relata la historia de sus abuelos que en el 1947 llegaron a Bari como refugiados/as parte del éxodo istriano-dálmata. "Estaban organizados/as en grandes cabañas que llamaban padiglioni (pabellones) donde vivían todas las familias juntas en el mismo gran espacio. Las paredes divisorias eran mantas colgadas y la vida cotidiana en la precariedad se basaba en el compartir costumbres, espacios e intimidad"6. Su abuela recuerda que no existían llaves que pudieran guardar las pocas cosas que cada familia tenía porqué ya lo habían perdido todo. Entre sus preocupaciones no se encontraban ni el miedo ni la necesidad de seguridad, y mucho menos el apego a unas pertenencias que ya no existían.

Esta comparación nos lleva a pensar que el sentimiento de seguridad y privacidad es entonces parte de una lógica occidental y capitalista y concretamente, en el caso de los refugios de IKEA, de una lógica basada en valores suecos occidentales.

En la temporada 2016-17 el Museo de Arte Moderno MoMA de Nueva York realiza la exposición Insecurities: Tracing Displacement and Shelter. Esta exposición explora las nociones de refugio a la luz de las emergencias mundiales de los/as refugiados/as. En ella se exhibe un ejemplar del refugio Better Shelter, expuesto como obra de arte contemporánea. Los comisarios muestran de forma evidente cuales son las motivaciones de su preocupación por los campos de refugiados. Según ellos, si antes "los campamentos de refugiados/as se consideraban temporales, ahora ya no lo son, visto que se han convertido en un lugar para examinar cómo los derechos humanos cruzan y complican la construcción de ciudades"7 En este sentido el MoMA se pregunta de qué manera pueden arquitectónicamente transformarse los campos de refugiados/as

3 “3.5 Square Meter - Marta Terne (Better Shelter). A home for all”. Vimeo <https://vimeo.com/214571667> [Consulta: 12 de septiembre 2019].

${ }^{4}$ Ibídem

5 ideadestroyingmuros es un grupo artístico transcultural feminista que se sitúa en la creación comunitaria del cual formamos parte.

${ }^{6}$ Canova Jordana es parte integrante del grupo artístico ideadestroyingmuros. En: CANOVA, Jordana, CORPS DE TRADUCTION. Déplacements géopolitico-sexuels et artistico-géopolitiques. Analyse de trois pratiques quotidiennes, autrement communautaires et diasporiques dans le contexte européen contemporain. Université Paris VIII, Paris, 2015.

7 DESINGBOOM. MoMA's 'insecurities' exhibition examines global displacement and shelter

<http://www.designboom.com/architecture/moma-insecurities-tracing-displacement-and-shelter-exhibition-11-22-2016/> [Consulta: 15 de septiembre 2019]. 
en futuras ciudades. O si -como la historia nos ha enseñado- los refugios pasarán de ser contenedores temporales a casas permanentes, mientras que los campos de refugiados/as se convertirán en nuevas ciudades.

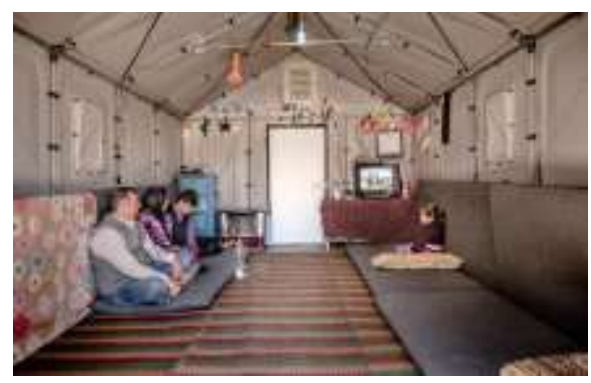

Fig. 2 Interior de un prototipo de refugio en el campamento de refugiados de Kawergosk, Erbil, Iraq.

Fig. 3 Better Shelter. The Museum Of Modern Art. Better Shelter. Foto: Jonathan Muzikar (C) 2016 The Museum Of Modern Art.

¿Cómo resignificarán las generaciones futuras estos espacios? ¿Serán un destino real para las segundas y terceras generaciones?

\section{Desde la propiedad privada hacia las casas comunitarias}

Nuestras historias genealógicas son diferentes y nos guían y ayudan a nuestros/as hijos/as a crecer en las diversidades. Una de nuestras historias viene de un éxodo -como hemos comentado anteriormente- y de la renuncia a todas las propriedades frente a las nacionalizaciones impuestas por el nuevo gobierno socialista de Yugoslavia. Volver a comprar una casa en el mismo sitio 70 años después nos lleva a pensarnos como vivir la propiedad privada de forma diferente. Croacia -antiguo territorio yugoslavo- está pasando su época de máxima explotación turística y capitalista. La propiedad privada es el principal valor occidental y el más respetado. Al tratarse de un valor importado es más radical su práctica, pero también hay huecos para alternativas y resistencias.

De hecho ¿qué otras formas de relacionarnos en los espacios comunes que se alejen del sentimiento de propiedad privada podemos plantearnos? ¿Y cómo equilibrarnos en lo cotidiano entre personas de diferentes procedencias? ¿Quién tiene que integrarse y a qué valores?

En nuestra cotidianidad habitada y atravesada por personas de diferentes orígenes (entre diáspora senegalesa, del este europeo, de Abya-Yala y del contexto europeo occidental) hemos decidido dejar las puertas de nuestras casas abiertas para forzar y transformar la costumbre que nos ha formado para preservar un sentimiento de propiedad. Se trata de pisos contiguos en el mismo edificio. En un principio los/as vecinos/as, al no estar familiarizados/as, se preocupaban, cuando dejabamos la puerta abierta y más todavía cuando dejabamos las llaves colgando fuera de la puerta cerrada. Con el tiempo han entendido que no tenemos nada y nada que temer. Utilizamos la práctica de hacer copias de llaves y dejarlas a las personas que atraviesan keurgumak $^{8}$ para que todo el mundo se sienta en casa, para que el control sobre el abrir y cerrar la puerta sea un acción transformadora de responsabilidad y cuidado. De esta forma keurgumak es la casa donde todos y todas están implicados en crear confianza.

Diferentes referentes nos han iluminado y acompañado en esta elección.

Claire Fontaine, colectivo artístico afincado en París, realizan una serie de obras sobre cómo transformar el valor de la propiedad privada. En 2004 realizan Passe-partout (Paris 10ème), una serie de ganzúas que permiten abrir cualquier puerta y en el título diferentes enlaces a tiendas donde poder realizar copias de estos Passe-partout.

\footnotetext{
${ }^{8}$ Keurgumak, que en wolof significa casa grande, es el espacio de la diáspora de nuestra vida cotidiana. este espacio diaspórico se encuentran en el barrio de Ruzafa en Valencia, España. En este espacio de la política-íntima tiene lugar todos los días el encuentro entre la diáspora italiana, la diáspora africana y en particular de Senegal.
} 
En 2007 realizan 10 rue Charlot / 5 rue saintonge colgando en las paredes de la Chantal Crousel Gallery las llaves que abren las puertas de la misma galería que las expone.

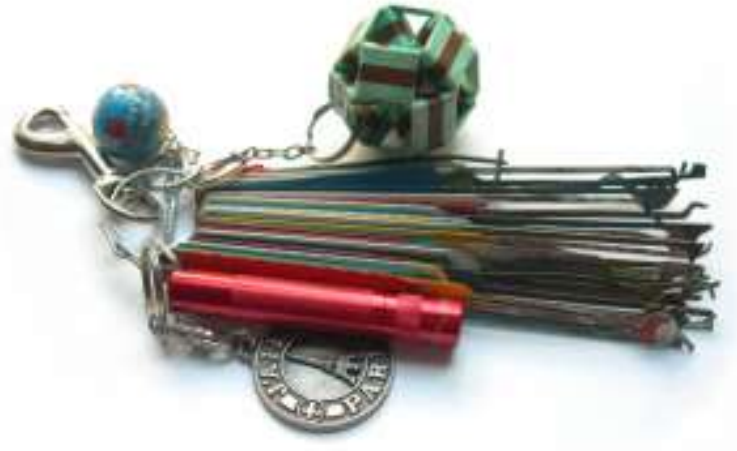

Fig. 4Passe-partout (Paris)2004

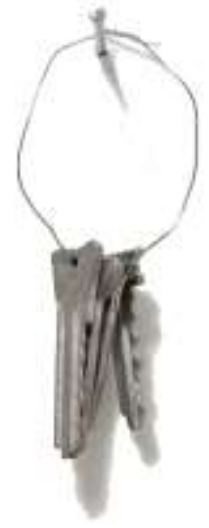

Fuente: Claire Fontaine

Fig.5 10 rue Charlot / 5 rue saintonge (Paris) 2007

Otro ejemplo para nosotras importante es la experiencia de un centro intercultural para mujeres en Verona.

Los espacios públicos, si por un lado pertenecen oficialmente a la propia comunidad, en realidad son administrados por profesionales cuyo papel puede reducirse a acciones burocráticas y de control. El movimiento político de las mujeres ha realizado una profunda revisión de las normas y jerarquías de la vida social, fundando lugares de libre acceso (casas de mujeres, centros contra la violencia, centros interculturales, librerías, bibliotecas) donde se promovió el saber femenino que propuso una revolución antes de todo en las relaciones intersubjetivas.

El centro intercultural para mujeres que conocemos está financiado por el Ayuntamiento y administrado por dos trabajadores sociales (un hombre y una mujer). La regla de la administración requiere que las personas asalariadas identificadas como responsables sean las únicas con las llaves, con el mandato de abrir y cerrar el lugar según el horario de oficina. Está claro que esta rutina habría obstaculizado y probablemente desactivado rápidamente la vida comunitaria de una casa que las mujeres de la ciudad percibían como común. Sin embargo, no todas las mujeres sintieron ganas de responsabilizarse del cuidado de los espacios de la casa: la llave se entregó solo a quienes conscientemente asumieron esta tarea. Esto ha significado que nadie en la Casa respira la división normalmente estructural y característica de los servicios, entre las figuras de operadores y usuarios. Cualquier mujer que se le reconozca su competencia puede emprender una actividad y, teniendo las llaves, llevarla a cabo en las formas y tiempos que considere apropiados o simplemente usar la casa a su manera, o sea estableciendo sus formas de estar allí, en relación con las necesidades de las otras. Es una acción que a menudo parte del deseo de estar presente, de un compromiso comunitario y político, del deseo de transformar las propias habilidades en un trabajo. Esta gestión del espacio y el tiempo permite, por ejemplo, a las mujeres que se ocupan cotidianamente del cuidado en los hogares privados tener un "hogar común" donde pueden reunirse los domingos todo el día, especialmente durante los meses fríos, o tomar cursos de baile de Sri Lanka gratis todas las noches.

Pero es también gracias a esto que se crean contextos de maternidad expandida que permiten a las mujeres una elasticidad en la organización diaria y unos recursos de relaciones horizontales. Esto es particularmente evidente en el caso, por ejemplo, de las mujeres nigerianas. Casi todos los días la entrada está poblada por madres, mujeres y niños/as del grupo étnico edo: Sandra es la interlocutora privilegiada de muchas. Comen juntas, hablan, se ayudan entre ellas, mantienen a los/as niños/as, se ayudan sobre cómo relacionarse con el mundo blanco, intercambian objetos útiles, hacen pequeños negocios entre ellas.

Es cierto que el trabajo subjetivo y compartido sobre la propiedad privada toca diferentes dimensiones de lo cotidiano de cada uno y cada una: las cosas que usamos todos los días, los bienes inmuebles, cómo nos relacionamos con los espacios públicos y comunitarios. 
Entre los pisos de keurgumak se mueven muchas cosas: platos, cargadores de móviles, chanclas, comida, etc. La mayoría de las veces los/as blancos/as con los/as cuales compartimos los pisos que no están acostumbrados/as a un cotidiano "otramente comunitario" (ideadestroyingmuros, 2015), a la hora de buscar algo suyo que no encuentran, lanzan la pregunta ¿dónde está mi “cosa”? implicando que alguien la haya sustraído y difundiendo la sospecha que este alguien sea africano. Si pensamos históricamente quién siempre en los siglos ha robado solo podemos decir que han sido los/as blancos/as con sus empresas colonizadoras. Los siglos de prácticas de saqueo están tan enraizados en la cultura occidental que hacen pensar a las personas blancas que todos somos iguales y en este caso iguales a los/as blancos/as, pero no todos/as somos así, y no todas las culturas están basadas en el despojo.

Las prácticas de compartir que apuestan hacia un devenir comunitario dependen del aprendizaje que permite la convivencia entre personas enraizadas en la cultura occidental y personas no occidentales. Se trata, para la parte occidental de perder el valor del control sobre las cosas y quién las tiene y desplazar este valor hacia el cuidado de los espacios y de las cosas que son útiles a todos/as.

El control sobre lo que hemos aprendido como "mío" abarca todo lo que nos rodea.

Joana, una amiga afrodescendiente de Brasil, un día nos pregunta desde qué edad tenemos la ropa individual de cada uno/a aquí en Europa. Nos cuenta que en su país hasta los 21 años, la ropa se comparte entre todos/as. Gracias a ella nos cuestionamos nuestra relación con el ropero y la ruta de la producción de textiles. Investigamos por ejemplo la relación entre la española Inditex, España y los lugares de producción-explotación en India o la relación neocolonial entre la empresa italiana Benetton y el territorio mapuche, es decir la ocupación de las tierras del pueblo para criar animales para producción textil. Así la narración de la experiencia de Joana nos da la fuerza para repensarnos, compartir lo que tenemos y practicar esta costumbre con los/as niño/as que viven o pasan por keurgumak.

Por otra parte en este recorrido de deconstrucción de una educación occidental arraigada en lo "mío" y lo "tuyo", nos sorprendimos de como esta idea de apego a las cosas materiales en cuanto propiedad se nos enseña desde temprano, como nos cuenta Mery: "Un día en la casa de mi madre en Italia mi sobrino Elia me pidió ayudarle a escribir su nombre y apellido en todos los lápices de colores que tenía. Los lápices venían ya de fábrica con un espacio blanco y la tarea de uno de los primeros días del cole era la de marcarlos con su nombre". Este hecho nos dió mucho que pensar. En la escuela italiana a los/as niños/as de 5-6 años en lugar de enseñarle la práctica de compartir de una forma equilibrada se le enseña a dividir lo que es la propiedad. ¿Qué pasa si los colores son pasados de mano en mano o prestado por los/as hermanos/as mayores?

Los baye fall $^{9}$ cuando le hablamos de la fase del "mío" que supuestamente pasan todos los/as niñas occidentales al crecer, nos cuentan que en Senegal las mismas madres si se dan cuenta de que alguien quiere algo solo para él/ella mismo/a, por ejemplo una pelota, se la dan directamente a los/as otros/as niños/as con quien el o la hija estaba jugando. Evidentemente esta fase, no es un momento natural de la vida de todos/as, más bien es una educación impuesta hacia unas determinadas relaciones con las cosas directamente impulsada por los padres y la sociedad occidental.

Por lo que concierne la gestión de los espacios inmuebles, hemos repensado la propiedad privada como una estrategia de resistencia útil frente a posibles desalojos y capaz de garantizar la supervivencia de vida comunitaria.

A su vez los ejemplos de convivencia comunitaria de los baye fall en Mbacke Kadior son fuentes de inspiración por su compromiso espiritual, ecológico, pacífico y sostenible. Así como el espacio mismo de las dairas, lugar de encuentro espiritual de la comunidad mourid y baye fall en la diáspora, son ejemplos de una organización también económica capaz de sostener a la comunidad.

\footnotetext{
${ }^{9}$ Los baye fall (o baay faal) son, en Senegal, una rama de la hermandad de mourides, una orden islámica sufí fundada por Cheikh Ibrahima Fall. El bayfalismo se ha desarrollado a partir del ejemplo y de las enseñanzas de Cheick Ahmadou Bamba, teólogo musulmán morabito sufí, que a finales del siglo XIX y principio del siglo XX resistió a la colonización francesa. Su discípulo Ibrahima Fall, descendiente directo de la familia real de Damel Dethialaw Atmane Fall, de la nobleza Geer de Cadior, puso en práctica los preceptos de su maestro, poniéndose al servicio de los demás y ofreciendo su trabajo a dios. La diáspora económica senegalesa involucra la comunidad baye fall que, gracias a sus valores, consigue mantenerse unida, integra, ayudarse y representar un referente "otramente comunitario" para los sujetos blancos occidentales. Los baye fall mantienen el orgullo de sus orígenes en los procesos poscoloniales que los atraviesan, implicándose aunque en la distancia, en la construcción económica y espiritual de la sociedad senegalesa.
} 
En Brescia, en el noroeste italiano, esta misma comunidad baye fall después de numerosos problemas en dar continuidad a la daira por el rechazo racista, han elegido comprar un inmueble donde poder encontrarse sin que nadie los/as echara. En este caso la compra del edificio ha transformado la propiedad privada en una práctica comunitaria de protección que asegurara el estar y una continuidad en el tiempo de esta comunidad.

La daira de València està enfrentándose a los mismos problemas de rechazo y eligiendo el mismo camino: buscar un espacio grande y acogedor para todos y todas.

A raíz de que la explotación inmobiliaria pusiera en riesgo la cotidianidad de keurgumak, subiendo los alquileres y haciéndonos sentir amenazados/as a quedarnos en la calle por el crecimiento de pisos turísticos, nos hizo dar más urgencia a lo que estábamos pensando: la compra de un piso en Valencia donde poder tener una base. Poder poner en común el dinero familiar de una de nosotras para esta operación nos ha llevado a asumir todavía más responsabilidad para repensar otras formas de propiedad que comprendieran la necesidad de mantener vivo un espacio comunitario.

\section{Referencias}

Alga, M. L. (2018). Etnografia "terrona" de sujetos excéntricos. Prácticas, narrativas y representaciones contra el racismo y el homofobia en Italia. Barcelona: Bellaterra.

BETTER SHELTER.ORG <http://bettershelter.org/> [Consulta: 12 de septiembre 2019].

Canova, J. (2015). Corps de traduction. Déplacements géopolitico-sexuels et artistico-géopolitiques. Analyse de trois pratiques quotidiennes, autrement communautaires et diasporiques dans le contexte européen contemporain. Tesis de doctorado. Paris: Université Paris VIII. <http://www.theses.fr/2016PA080012> [Consulta: 12 de septiembre 2019].

DesingBoom. MoMA's 'insecurities' exhibition examines global displacement and shelter. <https://www.designboom.com/architecture/moma-insecurities-tracing-displacement-and-shelter-exhibition-11-22-2016/> [Consulta: 12 de septiembre 2019].

ENGELS, F. (1970). El origen de la familia. La propriedad privada y el Estado. Madrid: Editorial Fundamento.

Favaretto, M. (2017). Estado, economía y sexualidad en la obra de Pier Paolo Pasolini. La creación artística: desde la singularidad pasoliniana hacia la dimensión comunitaria. Tesis de doctorado. Valencia: Universitat Politècnica de València, <https://riunet.upv.es/handle/10251/90490> [Consulta: 12 de septiembre 2019].

FEDERICI, S. (2018). Reincantare il mondo. Femminismo e politica dei commons. Verona: Ombre Corte.

IDEADESTROYingmuros (2015) "Keurgumak-casa grande. Ejemplo diferentemente comunitario" En Metáforas de la multitud. III congreso Internacional Estética y Política. Valencia: Universidad Politécnica de Valencia Editorial. 156-169.

IveKovic, R. (2015). "Dejar con la guerra de Europa a los migrantes" en ideadestroyingmuros. nārang: genealogía de un souvenir. Castellón: Idensitat.

“3.5 Square Meter - Marta Terne (Better Shelter). A home for all”. Vimeo <https://vimeo.com/214571667> [Consulta: 12 de septiembre 2019]. 